\title{
Pasireotide for acromegaly: long-term outcomes from an extension to the Phase III PAOLA study
}

\author{
Annamaria Colao', Marcello D Bronstein ${ }^{2}$, Thierry Brue ${ }^{3}$, Laura De Marinis ${ }^{4}$, Maria Fleseriu ${ }^{5}$, Mirtha Guitelman ${ }^{6}$, \\ Gerald Raverot ${ }^{7}$, Ilan Shimon ${ }^{8}$, Jürgen Fleck ${ }^{9}$, Pritam Gupta ${ }^{10}$, Alberto M Pedroncelli9 and Mônica R Gadelha ${ }^{11}$ \\ ${ }^{1}$ Università Federico II di Napoli, Naples, Italy, ${ }^{2}$ University of São Paulo Medical School, São Paulo, Brazil, ${ }^{3}$ Aix-Marseille Université, \\ Institut National de la Santé et de la Recherche Médicale INSERM U1251, Marseille Medical Genetics and Assistance Publique Hôpitaux \\ de Marseille (APHM), Hôpital de la Conception, Marseille, France, ${ }^{4}$ Università Cattolica del Sacro Cuore, Rome, Italy, \\ ${ }^{5}$ Northwest Pituitary Center, Oregon Health \& Science University, Portland, Oregon, USA, ${ }^{6}$ Endocrinology Division, \\ Carlos G Durand Hospital, Buenos Aires, Argentina, ${ }^{7}$ Groupement Hospitalier Est, Hospices Civils de Lyon and Lyon 1 \\ University, Lyon, France, ${ }^{8}$ Rabin Medical Center and Sackler School of Medicine, Tel-Aviv University, Petah-Tiqva, \\ Israel, ${ }^{9}$ Novartis Pharma AG, Basel, Switzerland, ${ }^{10}$ Novartis Healthcare Private Limited, Hyderabad, India, and \\ ${ }^{11}$ Hospital Universitário Clementino Fraga Filho, Universidade Federal do Rio de Janeiro, Rio de Janeiro, Brazil \\ Correspondence \\ should be addressed \\ to A Colao \\ Email \\ colao@unina.it
}

\begin{abstract}
Objective: In the Phase III PAOLA study (clinicaltrials.gov: NCT01137682), enrolled patients had uncontrolled acromegaly despite $\geq 6$ months of octreotide/lanreotide treatment before study start. More patients achieved biochemical control with long-acting pasireotide versus continued treatment with octreotide/lanreotide (active control) at month 6 . The current work assessed the extent of comorbidities at baseline and outcomes during a long-term extension.

Design/methods: Patients receiving pasireotide 40 or $60 \mathrm{mg}$ at core study end could continue on the same dose in an extension phase if biochemically controlled or receive pasireotide $60 \mathrm{mg}$ if uncontrolled. Uncontrolled patients on active control were switched to pasireotide $40 \mathrm{mg}$, with the dose increased at week 16 of the extension if still uncontrolled (crossover group). Efficacy and safety are reported to 304 weeks ( $\sim 5.8$ years) for patients randomized to pasireotide (core + extension), and 268 weeks for patients in the crossover group (extension only).

Results: Almost half $(49.5 \%$; 98/198) of patients had $\geq 3$ comorbidities at core baseline. During the extension, 173 patients received pasireotide. Pasireotide effectively and consistently reduced GH and IGF-I levels for up to 5.8 years' treatment; $37.0 \%$ of patients achieved $\mathrm{GH}<1.0 \mu \mathrm{g} / \mathrm{L}$ and normal IGF-I at some point during the core or extension. Improvements were observed in key symptoms. The long-term safety profile was similar to that in the core study; 23/173 patients discontinued treatment because of adverse events.

Conclusions: In this patient population with a high burden of comorbid illness, pasireotide was well tolerated and efficacious, providing prolonged maintenance of biochemical control and improving symptoms.
\end{abstract}

\section{Introduction}

Acromegaly is an endocrine disorder most commonly caused by chronic excess secretion of growth hormone (GH) from a pituitary adenoma and subsequent hepatic hypersecretion of insulin-like growth factor 1 (IGF-I) (1). Chronic hypersecretion of GH and IGF-I results in multiple comorbidities, particularly cardiometabolic complications (2), that not only increase mortality risk but also imposes a substantial burden of illness on patients. Achieving biochemical control in line with guideline recommendations (3) can reduce morbidity and 
may mitigate the increased mortality risk associated with acromegaly $(4,5)$.

First-generation somatostatin analogues (long-acting octreotide and lanreotide) are the current first-line standard of medical care in patients with acromegaly (3). Despite the clinical success of these agents (6), many patients remain uncontrolled $(7,8)$ and therefore exposed to the deleterious health consequences associated with elevated GH and IGF-I levels. Pasireotide is a multireceptortargeted second-generation somatostatin analogue that has demonstrated superior efficacy over first-generation somatostatin analogues in two randomized, prospective, Phase III clinical studies $(9,10)$. In study C2305, conducted in patients with active acromegaly who had not received medical therapy at study entry, biochemical control (defined as GH $<2.5 \mu \mathrm{g} / \mathrm{L}$ and normal IGF-I) was achieved by a significantly greater proportion of patients receiving long-acting pasireotide than long-acting octreotide (31.3 vs $19.2 \% ; P=0.007)$ at month $12(9)$. The PAOLA study (C2402) evaluated patients with uncontrolled acromegaly while on maximal approved doses of long-acting octreotide or lanreotide prior to the start of the study (10). Significantly more patients who were treated with long-acting pasireotide achieved biochemical control (GH $<2.5 \mu \mathrm{g} / \mathrm{L}$ and normal IGF-I) than patients who continued treatment with long-acting octreotide or lanreotide at month 6 (15.4\% (long-acting pasireotide $40 \mathrm{mg}$ ) and $20.0 \%$ (long-acting pasireotide $60 \mathrm{mg}$ ) vs $0 \% ; P=0.0006$ and $P<0.0001$, respectively) (10).

The current work includes a detailed analysis of the baseline comorbidities of patients who participated in the PAOLA study, along with efficacy and safety findings for up to 5.8 years of follow-up. Notably, biochemical control in the core phase of the PAOLA study was defined according to accepted treatment guidelines at the time of study start (11). However, updated treatment guidelines have now been published recommending a more stringent definition of biochemical control $(\mathrm{GH}<1.0 \mu \mathrm{g} / \mathrm{L}$ and normalized IGF-I) (3). To ensure the clinical relevance of the data reported here, biochemical control in the extension phase of the PAOLA study is defined according to these up-to-date treatment guidelines.

\section{Methods}

\section{Eligibility criteria}

Patient eligibility criteria for the core study have been reported previously (10). Briefly, male and female patients aged $\geq 18$ years with uncontrolled acromegaly, defined as mean GH $>2.5 \mu \mathrm{g} / \mathrm{L}$ and IGF-I $>1.3$ times the sex- and age-adjusted upper limit of normal (ULN), were enrolled. Patients had received treatment with long-acting octreotide $30 \mathrm{mg}$ or lanreotide $120 \mathrm{mg} / 28$ days for $\geq 6$ months prior to screening. Patients could have had $\geq 1$ prior pituitary surgery and could have received combination therapy with a dopamine agonist or GH-receptor antagonist.

The study was conducted in accordance with the Declaration of Helsinki, and an independent ethics committee or institutional review board for each study site approved the study protocol (see Supplementary Appendix for full details, see section on supplementary materials given at the end of this article). All patients provided written informed consent to participate in the study.

\section{Study design}

This was an extension to a prospective, multicentre, randomized, parallel-group, 6-month core study. In the core study, patients were randomized to double-blind long-acting pasireotide $40 \mathrm{mg} / 28$ days or long-acting pasireotide $60 \mathrm{mg} / 28$ days, or continued treatment with open-label long-acting octreotide $30 \mathrm{mg}$ or lanreotide 120 mg every 28 days (10). No dose increases were permitted during the core phase. All patients who completed the core study were eligible to participate in the extension phase. The last visit of the core study was considered as the first visit of the extension phase. The phase between the end of the core study and the second visit of the extension phase was defined as the 'bridging phase', during which patients continued to receive their randomized treatment. After this time, patients who were receiving pasireotide 40 or $60 \mathrm{mg}$ and who had $\mathrm{GH}<2.5 \mu \mathrm{g} / \mathrm{L}$ and normalized IGF-I at the end of the core study continued to receive the same dose of double-blind pasireotide during the extension. Patients who were uncontrolled at week 24 of the core study with pasireotide 40 or $60 \mathrm{mg}$ could receive open-label pasireotide $60 \mathrm{mg}$. Patients in the active control group who were uncontrolled at week 24 of the core study were switched to open-label pasireotide 40 $\mathrm{mg}$ (referred to hereafter as the crossover group); a dose increase to pasireotide $60 \mathrm{mg}$ was permitted at week 16 of the extension phase if $\mathrm{GH}<2.5 \mu \mathrm{g} / \mathrm{L}$ and normalized IGF-I was not achieved. Dose decreases of $20 \mathrm{mg}$ were permitted for tolerability issues in patients randomized to receive pasireotide. If a patient in the crossover group experienced a severe drug-related adverse event (AE), dose decreases to the next-available lower dose were permitted. 
Previous dosing was resumed once the tolerability issue had resolved.

The principal investigator was responsible for educating the patient on the signs and symptoms of hyperglycaemia. It was recommended that established guidelines by expert international diabetes associations, such as the American Diabetes Association and European Association for the Study of Diabetes, were followed for the management of any instances of hyperglycaemia during the study. Any patients in whom fasting plasma glucose (FPG) levels were $>130 \mathrm{mg} / \mathrm{dL}$, or 2 -h post-prandial capillary glucose was $\geq 180 \mathrm{mg} / \mathrm{dL}$ on two consecutive measurements that were $\sim 14$ days apart, and/or glycated haemoglobin $\left(\mathrm{HbA}_{1 \mathrm{c}}\right)$ was $>7 \%$ were to be evaluated by a diabetes specialist for appropriate treatment.

\section{Assessments}

Assessments reported here include the following: proportion of patients with biochemical control ( $\mathrm{GH}<1.0$ $\mu \mathrm{g} / \mathrm{L}$ and normalized IGF-I); mean GH and IGF-I levels over time; number of patients who had a dose increase/decrease in the extension phase; changes in signs and symptoms; baseline characteristics of early and late responders during the extension phase; and safety. Additionally, baseline demographics according to comorbidity group were determined. Patients were classified into five groups of comorbidities commonly associated with acromegaly: glucose-related, endocrine-related, lipidrelated, vascular, and all other acromegaly-related disorders (see Supplementary Appendix for definitions). Baseline demographics by comorbidity group were determined for the total population. Details on the GH and IGF-I assays used have been published previously (10).

\section{Definitions of diabetic status}

- Diabetic was defined as patients taking antidiabetic medication, or with prior history of diabetes mellitus, or with $\mathrm{HbA}_{1 \mathrm{c}} \geq 6.5 \%(\geq 47.5 \mathrm{mmol} / \mathrm{mol})$ or $\mathrm{FPG} \geq 126$ $\mathrm{mg} / \mathrm{dL}(\geq 7.0 \mathrm{mmol} / \mathrm{L})$.

- Pre-diabetic was defined as patients not qualifying as diabetic and with $\mathrm{HbA}_{1 \mathrm{c}} \geq 5.7 \%(\geq 38.8 \mathrm{mmol} / \mathrm{mol})$ and $<6.5 \%(<47.5 \mathrm{mmol} / \mathrm{mol})$ or $\mathrm{FPG} \geq 100(\geq 5.6 \mathrm{mmol} / \mathrm{L})$ and $<126 \mathrm{mg} / \mathrm{dL}(<7.0 \mathrm{mmol} / \mathrm{L})$.

- Normal glucose tolerance was defined as patients not qualifying as diabetic or pre-diabetic and with $\mathrm{HbA}_{1 \mathrm{c}}$ $<5.7 \%(<38.8 \mathrm{mmol} / \mathrm{mol})$ and/or $\mathrm{FPG}<100 \mathrm{mg} / \mathrm{dL}$ $(<5.6 \mathrm{mmol} / \mathrm{L})$.

\section{Statistical analyses}

Treatment groups were based on randomized treatment at core baseline. Efficacy and safety are reported up to study end: 303.9 weeks ( 5.8 years) after start of treatment (core+extension) for patients randomized to receive pasireotide, and 268.0 weeks for the crossover group (extension only). Baseline conditions and patient demographics, as well as efficacy and safety data, are summarized descriptively.

\section{Results}

\section{Core study baseline conditions and patient demographics}

One hundred and ninety-eight patients entered the core study. Individual disease conditions, as reported by the investigator, comprising each comorbidity group at core baseline $(n=198)$ are shown in Table 1 . Patient baseline characteristics were similar across the comorbidity groups, with glucose- and endocrine-related comorbidities the most common in the overall patient population (Table 2); $49.5 \%$ (98/198) of patients had comorbidities in three or more comorbidity groups (Table 3 and Supplementary Fig. 1). Of the 198 patients in the core study, $67.2 \%$ $(132 / 198)$ were defined according to predefined study criteria as diabetic, $20.7 \%(41 / 198)$ as pre-diabetic, and $11.6 \%(23 / 198)$ as having normal glucose tolerance. Of the 145 patients with investigator-reported baseline glucose-related disorders, $71.7 \%$ were defined as diabetic at baseline, while $28.3 \%$ were pre-diabetic at baseline (Table 2).

\section{Patient disposition: core phase}

In the pasireotide $40 \mathrm{mg}$, pasireotide $60 \mathrm{mg}$ and crossover groups, respectively, 59 (90.8\%), 57 (87.7\%) and 65 (95.6\%) patients completed the 24-week core study (Supplementary Fig. 1); reasons for discontinuation included AEs $(n=2,4$ and 0$)$, consent withdrawal $(n=2$, 2 and 2), administrative problems $(n=2,1$ and 0$)$ and protocol deviations ( $n=0,1$ and 1$)$.

\section{Patient disposition: extension phase}

Of the 174 patients who entered the extension phase, 173 were treated: pasireotide $40 \mathrm{mg}, n=57$; pasireotide $60 \mathrm{mg}, n=54$; crossover, $n=62$. Overall, $65.9 \%$ (114/173) 
Table 1 Most common conditions within each comorbidity group classification reported by the investigator at core baseline (occurring in $\geq 5 \%$ of patients in any treatment group). Comorbidities listed as reported by the investigator. Data based on preferred terms from patient medical history. Complete list of comorbidities for each comorbidity group classification is provided in the Supplementary Appendix.

\begin{tabular}{l} 
Comorbidity, $\boldsymbol{n}$ (\%) \\
\hline Vascular disorders \\
Hypertension \\
Glucose-related disorders \\
Diabetes mellitus \\
Impaired glucose tolerance \\
Type 2 diabetes mellitus \\
Lipid-related disorders \\
Dyslipidaemia \\
Hypercholesterolaemia \\
Endocrine-related disorders \\
Goitre \\
Hypothyroidism \\
Adrenal insufficiency \\
Hypopituitarism \\
Hyperprolactinaemia \\
Hypogonadism \\
Diabetes insipidus \\
Secondary hypothyroidism \\
Secondary hypogonadism \\
Secondary adrenocortical insufficiency \\
Other acromegaly-related disorders \\
Depression \\
Headache \\
Osteoarthritis \\
Carpal tunnel syndrome \\
Carpal tunnel decompression \\
Insomnia \\
Osteoporosis \\
Aortic valve incompetence \\
Haemangioma of the liver \\
\hline
\end{tabular}

$\begin{gathered}\text { Long-acting pasireotide } \\ \mathbf{4 0} \mathbf{~} \mathbf{g}, \boldsymbol{n}=65\end{gathered}$
$17(26.2)$
$18(27.7)$
$10(15.4)$
$6(9.2)$
$10(15.4)$
$6(9.2)$
$9(13.8)$
$10(15.4)$
$8(12.3)$
$7(10.8)$
$5(7.7)$
$4(6.2)$
$4(6.2)$
$6(9.2)$
$5(7.7)$
$1(1.5)$
$7(10.8)$
$4(6.2)$
$4(6.2)$
$5(7.7)$
$3(4.6)$
$2(3.1)$
$3(4.6)$
$0(0.0)$
$0(0.0)$

\begin{tabular}{|c|c|}
\hline $\begin{array}{l}\text { Long-acting pasireotide } \\
\qquad \mathbf{6 0} \mathbf{~ m g}, n=65\end{array}$ & $\begin{array}{c}\text { Active control, } \\
n=68\end{array}$ \\
\hline $27(41.5)$ & 36 (52.9) \\
\hline $11(16.9)$ & $16(23.5)$ \\
\hline $10(15.4)$ & $11(16.2)$ \\
\hline $9(13.8)$ & $4(5.9)$ \\
\hline $15(23.1)$ & $8(11.8)$ \\
\hline $5(7.7)$ & $5(7.4)$ \\
\hline $14(21.5)$ & $23(33.8)$ \\
\hline $10(15.4)$ & $12(17.6)$ \\
\hline $6(9.2)$ & $10(14.7)$ \\
\hline $4(6.2)$ & $5(7.4)$ \\
\hline $5(7.7)$ & $3(4.4)$ \\
\hline $6(9.2)$ & $5(7.4)$ \\
\hline $4(6.2)$ & $2(2.9)$ \\
\hline $4(6.2)$ & $4(5.9)$ \\
\hline $5(7.7)$ & $6(8.8)$ \\
\hline $5(7.7)$ & $3(4.4)$ \\
\hline $2(3.1)$ & $4(5.9)$ \\
\hline $3(4.6)$ & $1(1.5)$ \\
\hline $3(4.6)$ & $6(8.8)$ \\
\hline $1(1.5)$ & $5(7.4)$ \\
\hline $2(3.1)$ & $4(5.9)$ \\
\hline $4(6.2)$ & $1(1.5)$ \\
\hline $2(3.1)$ & $4(5.9)$ \\
\hline $1(1.5)$ & $4(5.9)$ \\
\hline $0(0.0)$ & $4(5.9)$ \\
\hline
\end{tabular}

were defined as diabetic, $23.7 \%(41 / 173)$ as pre-diabetic, and $10.4 \%(18 / 173)$ as having normal glucose tolerance at baseline. In total, 28 (49.1\%), 25 (46.3\%), and 34 (54.8\%) patients in the pasireotide $40 \mathrm{mg}, 60 \mathrm{mg}$, and crossover groups, respectively, completed the extension phase of the study (Supplementary Fig. 1). Discontinuations during the extension phase were as follows: 29 patients from the pasireotide $40 \mathrm{mg}$ group (unsatisfactory effect, $n=15$; withdrawal of consent, $n=6$; $\mathrm{AE}, n=4$; death, $n=2$; protocol deviation, $n=2$ ), 29 patients from the pasireotide $60 \mathrm{mg}$ group (unsatisfactory effect, $n=9$; withdrawal of consent, $n=8$; $\mathrm{AE}, n=8$; administrative issues, $n=2$; loss to follow-up, $n=1$; protocol deviation, $n=1$ ), and 28 patients from the crossover group (unsatisfactory effect, $n=13$; withdrawal of consent, $n=8 ; \mathrm{AE}, n=7$ ). Median (range) duration of pasireotide exposure from start of treatment to end of study was 152.1 (11.9-303.9) weeks in the pasireotide $40 \mathrm{mg}$ group, 149.6 (4.0-295.4) weeks in the pasireotide $60 \mathrm{mg}$ group, and 201.6 (16.0-268.0) weeks in the crossover group.

\section{Long-term efficacy: biochemical response}

In all three treatment groups, mean GH and IGF-I levels were consistently suppressed throughout the duration of the extension phase until study end (Table 3). Biochemical response rates $(\mathrm{GH}<1.0 \mu \mathrm{g} / \mathrm{L}$ and normal IGF-I) varied throughout the extension: $1.8-10.5 \%$ and $3.7-20.4 \%$ for patients randomized to pasireotide $40 \mathrm{mg}$ and $60 \mathrm{mg}$, respectively, and 1.6-11.3\% for patients in the crossover group (Table 4).

Sixty-four patients (37.0\%) achieved $\mathrm{GH}<1.0 \mu \mathrm{g} / \mathrm{L}$ and normal IGF-I at some point during the core or extension phase. Of these patients, 13 (20.3\%) achieved a first response within 3 months of treatment initiation, nine $(14.1 \%)$ did so after 3-6 months of treatment, and 
Table 2 Core study baseline demographics by comorbidity group. Data based on 198 patients in the core baseline population.

\begin{tabular}{|c|c|c|c|c|c|}
\hline & $\begin{array}{l}\text { Glucose-related } \\
\text { disorders }\end{array}$ & $\begin{array}{c}\text { Endocrine-related } \\
\text { disorders }\end{array}$ & $\begin{array}{l}\text { Vascular } \\
\text { disorders }\end{array}$ & $\begin{array}{l}\text { Lipid-related } \\
\text { disorders }\end{array}$ & $\begin{array}{l}\text { All other acromegaly- } \\
\text { related disorders }\end{array}$ \\
\hline$n$ & 145 & 127 & 80 & 56 & 111 \\
\hline Mean age, years (s.D.) & $47.1(14.0)$ & $45.8(13.7)$ & $51.9(12.2)$ & $52.3(13.6)$ & $48.6(12.6)$ \\
\hline \multicolumn{6}{|l|}{ Gender, $n(\%)$} \\
\hline Male & $59(40.7)$ & $56(44.1)$ & $35(43.8)$ & $17(30.4)$ & 41 (36.9) \\
\hline Female & $86(59.3)$ & $71(55.9)$ & $45(56.3)$ & $39(69.6)$ & $70(63.1)$ \\
\hline Mean weight, kg (s.D.) & $85.4(18.9)$ & $86.6(19.9)$ & $89.9(20.1)$ & $85.6(19.3)$ & $85.8(20.9)$ \\
\hline Mean BMI, kg/m² (s.D.) & $29.9(6.0)$ & $29.8(5.9)$ & $31.5(6.2)$ & $31.1(5.7)$ & $29.9(6.2)$ \\
\hline \multicolumn{6}{|l|}{ Baseline diabetic status, * $n(\%)$} \\
\hline Diabetic & $104(71.7)$ & $94(74.0)$ & $64(80.0)$ & $46(82.1)$ & $81(73.0)$ \\
\hline Pre-diabetic & $41(28.3)$ & $20(15.7)$ & $14(17.5)$ & 7 (12.5) & $21(18.9)$ \\
\hline Normal glucose tolerance & $0(0.0)$ & $13(10.2)$ & $1(1.3)$ & $3(5.4)$ & $9(8.1)$ \\
\hline Missing & $0(0.0)$ & $0(0.0)$ & $1(1.3)$ & $0(0.0)$ & $0(0.0)$ \\
\hline Mean baseline GH, $\mu \mathrm{g} / \mathrm{L}$ (S.D.) & $12.7(23.8)$ & $12.4(22.9)$ & 10.3 (13.9) & $9.0(15.8)$ & $10.6(20.7)$ \\
\hline Mean baseline IGF-I, x ULN (s.D.) & $2.9(1.1)$ & $2.7(1.1)$ & $3.1(1.1)$ & $3.0(1.1)$ & $2.9(1.1)$ \\
\hline
\end{tabular}

*See Methods section for definitions of diabetic status.

$42(65.6 \%)$ after at least 6 months of treatment (Table 5). For patients with a first response after 6 months, the median time to response in the pasireotide $40 \mathrm{mg}, 60$ $\mathrm{mg}$, and crossover groups, respectively, was $20.3(n=15)$, $18.4(n=15)$, and $26.8(n=12)$ months (range: 9.2-58.9 months). Patient characteristics at baseline were similar irrespective of time of first response (Table 5).

\section{Dose titration}

In patients randomized to pasireotide $40 \mathrm{mg}$ and for those in the crossover group who started with pasireotide 40 $\mathrm{mg}$ in the extension, 68.4\% (39/57) and 59.7\% (37/62), respectively, received a dose increase to $60 \mathrm{mg}$ during the extension phase; $28.2 \%(11 / 39)$ and $21.6 \%$ (8/37) of these patients, respectively, achieved $\mathrm{GH}<1.0 \mu \mathrm{g} / \mathrm{L}$ and normal IGF-I. For patients randomized to pasireotide $60 \mathrm{mg}, 9.3 \%$ $(5 / 54)$ had a dose decrease to $40 \mathrm{mg}$ because of AEs.

\section{Clinical symptoms of acromegaly}

Improvements in key symptoms of acromegaly (headache, fatigue, perspiration, paraesthesia and osteoarthralgia)

Table 3 Number of patients from the randomized population $(n=198)$ who had one or more comorbidities at baseline.

\begin{tabular}{l} 
Number of comorbidities \\
at baseline \\
\hline 1 \\
2 \\
3 \\
4 \\
5 \\
\hline
\end{tabular}

\begin{tabular}{c}
$\begin{array}{c}\text { Proportion of randomized } \\
\text { population, } n(\%)\end{array}$ \\
\hline $42(21.2)$ \\
$41(20.7)$ \\
$51(25.8)$ \\
$34(17.2)$ \\
$13(6.6)$
\end{tabular}

were observed in all treatment groups (Fig. 1). Symptoms emerged in a minority of patients in whom no symptoms were present at baseline (headache, $n=9 / 68$; fatigue, $n=14 / 48$; perspiration, $n=17 / 75$; osteoarthralgia, $n=16 / 56$; paraesthesia, $n=13 / 94)$, but these were generally mild to moderate in severity (Fig. 1).

\section{Safety and tolerability of long-acting pasireotide}

For patients randomized to pasireotide $40 \mathrm{mg}$ and $60 \mathrm{mg}$, $61 / 63$ (96.8\%) and 60/62 (96.8\%), as well as 61/62 (98.4\%) patients in the crossover group, experienced at least one AE. The most common AEs regardless of study drug relationship were hyperglycaemia $(39.7,40.3$, and $25.8 \%$, respectively), diabetes mellitus $(31.7,40.3$, and $29.0 \%$, respectively), and cholelithiasis $(34.9,33.9$, and $30.6 \%$, respectively; Table 6). AEs resulted in 18.5\% (32/173) of patients discontinuing treatment ( 9 patients each in the crossover group and those randomized to pasireotide 40 $\mathrm{mg}$, and 14 patients randomized to pasireotide $60 \mathrm{mg}$ ); of the patients in the pasireotide $40 \mathrm{mg}$ and $60 \mathrm{mg}$ arms, respectively, who stopped pasireotide treatment because of AEs, four and five discontinued during the core phase. Drug-related serious AEs were reported in 5 (7.9\%) patients randomized to pasireotide $40 \mathrm{mg}$ (anaemia $(n=1)$, abdominal pain $(n=1)$, cholecystitis $(n=1)$, cholelithiasis $(n=2)$, increased blood glucose $(n=1)$, hyperglycaemia $(n=1)$, diabetic metabolic decompensation $(n=1)$, deep vein thrombosis $(n=1)), 6(9.7 \%)$ patients randomized to pasireotide $60 \mathrm{mg}$ (bile duct stone $(n=1)$, cholecystitis $(n=1)$, cholelithiasis $(n=1)$, hyperglycaemia $(n=1)$, hypoglycaemia unawareness $(n=1)$, benign pituitary 
Table 4 Response rates ( $\mathrm{GH}<1.0 \mu \mathrm{g} / \mathrm{L}$ and normal IGF-I) during the extension phase.

$$
\text { Wee }
$$

\section{\begin{tabular}{l} 
Study visi \\
\hline Baseline $^{\dagger}$ \\
Week 52 \\
Week 112
\end{tabular}}

*Duration of pasireotide exposure in the crossover group was 24 weeks shorter than the 'study visit', as these patients did not receive pasireotide during the 24-week core phase; 'Baseline values are shown at core study baseline for the pasireotide $40 \mathrm{mg}$ and $60 \mathrm{mg}$ groups, and at extension baseline for the crossover group; ${ }^{\ddagger}$ Response rate was calculated (i) using the ITT principle for all patients who received pasireotide and (ii) for patients who reached the scheduled visit. ITT, intention to treat; pts, patients; sIGF-I, standardized IGF-I (IGF-I/ULN). tumour $(n=1)$, suicide attempt $(n=1))$, and $8(12.9 \%)$ patients in the crossover group (vertigo $(n=1)$, nausea $(n=1)$, acute cholecystitis $(n=1)$, cholecystitis $(n=1)$, cholelithiasis $(n=1)$, liver abscess $(n=1)$, diabetes mellitus $(n=2)$, hyperglycaemia $(n=1)$, dizziness $(n=1))$.

In total, five patients were hospitalized for events related to hyperglycaemia: two for events of worsening diabetes mellitus, one of which led to treatment discontinuation and was ongoing at last assessment, with the other resolving without requiring treatment discontinuation; two for hyperglycaemia, both of which resolved without requiring treatment cessation; and one for diabetic decompensation (grade 4 diabetes), which hyperosmolar state. Changes in values of FPG and $\mathrm{HbA}_{1 \mathrm{c}}$ from baseline to end of the extension phase in the three treatment arms are shown in Table 7.

There were two deaths during the extension phase, both in the pasireotide $40 \mathrm{mg}$ group: one patient died because of a brain oedema that was not suspected to be related to treatment, and one patient discontinued study treatment because of an $\mathrm{AE}$ of lung cancer that ultimately led to death.

\section{Hyperglycaemia management}

Across the three treatment groups, $75.0-100.0 \%$ of patients who were pre-diabetic or had normal glucose tolerance at baseline, and $31.3-55.3 \%$ of patients who were diabetic at baseline, had a last available $\mathrm{HbA}_{1 \mathrm{c}}$ value of $<7 \%(<53.0$ $\mathrm{mmol} / \mathrm{mol}$ ) at study end (Table 8 ).
Table 5 Baseline characteristics of early and late responders. Response defined as the first occurrence of a reduction of mean $\mathrm{GH}$ to $<1.0 \mu \mathrm{g} / \mathrm{L}$ and normalization of IGF-I after initiation of pasireotide in the core or extension phase. Data are presented as $n(\%)$ unless indicated otherwise.

\begin{tabular}{|c|c|c|c|c|c|c|c|c|c|}
\hline \multirow[b]{3}{*}{ First response } & \multicolumn{3}{|c|}{ Long-acting pasireotide $\mathbf{4 0} \mathbf{~ m g}, n=57$} & \multicolumn{3}{|c|}{ Long-acting pasireotide $60 \mathrm{mg}, n=54$} & \multicolumn{3}{|c|}{ Crossover to pasireotide, $n=62$} \\
\hline & & $>3-6$ & & & $>3-6$ & & & $>3-6$ & \\
\hline & $\leq 3$ months & months & $\geq 6$ months & $\leq 3$ months & months & $>6$ months & $\leq 3$ months & months & $>6$ months \\
\hline$n$ & 3 & 2 & 15 & 7 & 4 & 15 & 3 & 3 & 12 \\
\hline Age, years* & $50.3(4.9)$ & $50.5(2.1)$ & $\begin{array}{c}45.9 \\
(14.74)\end{array}$ & $\begin{array}{c}55.0 \\
(17.0)\end{array}$ & $\begin{array}{c}39.3 \\
(11.3)\end{array}$ & $\begin{array}{c}45.9 \\
(9.15)\end{array}$ & $\begin{array}{c}53.3 \\
(8.39)\end{array}$ & $\begin{array}{c}43.7 \\
(18.0)\end{array}$ & $\begin{array}{c}42.2 \\
(14.3)\end{array}$ \\
\hline Baseline $\mathrm{GH}, \mu \mathrm{g} / \mathrm{L}^{*}$ & $9.2(7.0)$ & $5.2(3.4)$ & $5.0(2.9)$ & $6.8(3.6)$ & $5.1(2.7)$ & $4.1(2.0)$ & $4.6(1.0)$ & $4.8(2.3)$ & $4.9(1.7)$ \\
\hline Baseline IGF-|* & $390.1(45.8)$ & $\begin{array}{c}442.2 \\
(228.0)\end{array}$ & $\begin{array}{c}592.8 \\
(133.6)\end{array}$ & $\begin{array}{c}658.8 \\
(233.5)\end{array}$ & $\begin{array}{c}477.8 \\
(108.1)\end{array}$ & $\begin{array}{c}626.7 \\
(155.4)\end{array}$ & $645.3(72.8)$ & $\begin{array}{c}633.7 \\
(174.0)\end{array}$ & $\begin{array}{c}592.4 \\
(161.4)\end{array}$ \\
\hline \multicolumn{10}{|l|}{ Sex, $n(\%)$} \\
\hline Male & $2(66.7)$ & $1(50.0)$ & $7(46.7)$ & $3(42.9)$ & $2(50.0)$ & $6(40.0)$ & $3(100.0)$ & $2(66.7)$ & $6(50.0)$ \\
\hline Female & $1(33.3)$ & $1(50.0)$ & $8(53.3)$ & $4(57.1)$ & $2(50.0)$ & $9(60.0)$ & $0(0.0)$ & $1(33.3)$ & $6(50.0)$ \\
\hline \multicolumn{10}{|c|}{ Tumour volume category at baseline, $n(\%)$} \\
\hline Microadenoma $^{\dagger}$ & $2(66.7)$ & $2(100.0)$ & $11(73.3)$ & $4(57.1)$ & $4(100.0)$ & $7(46.7)$ & $1(33.3)$ & $1(33.3)$ & $11(91.7)$ \\
\hline Macroadenoma & $0(0.0)$ & $0(0.0)$ & $1(6.7)$ & $0(0.0)$ & $0(0.0)$ & $1(6.7)$ & $0(0.0)$ & $0(0.0)$ & $0(0.0)$ \\
\hline Missing & $1(33.3)$ & $0(0.0)$ & $3(20.0)$ & $3(42.9)$ & $0(0.0)$ & $7(46.7)$ & $2(66.7)$ & $2(66.7)$ & $1(8.3)$ \\
\hline
\end{tabular}

${ }^{*}$ Data are presented as mean (S.D.); ${ }^{\dagger}$ corresponding to a tumour diameter of $\leq 10 \mathrm{~mm}$; ${ }^{\ddagger}$ corresponding to a tumour diameter of $>10 \mathrm{~mm}$. 

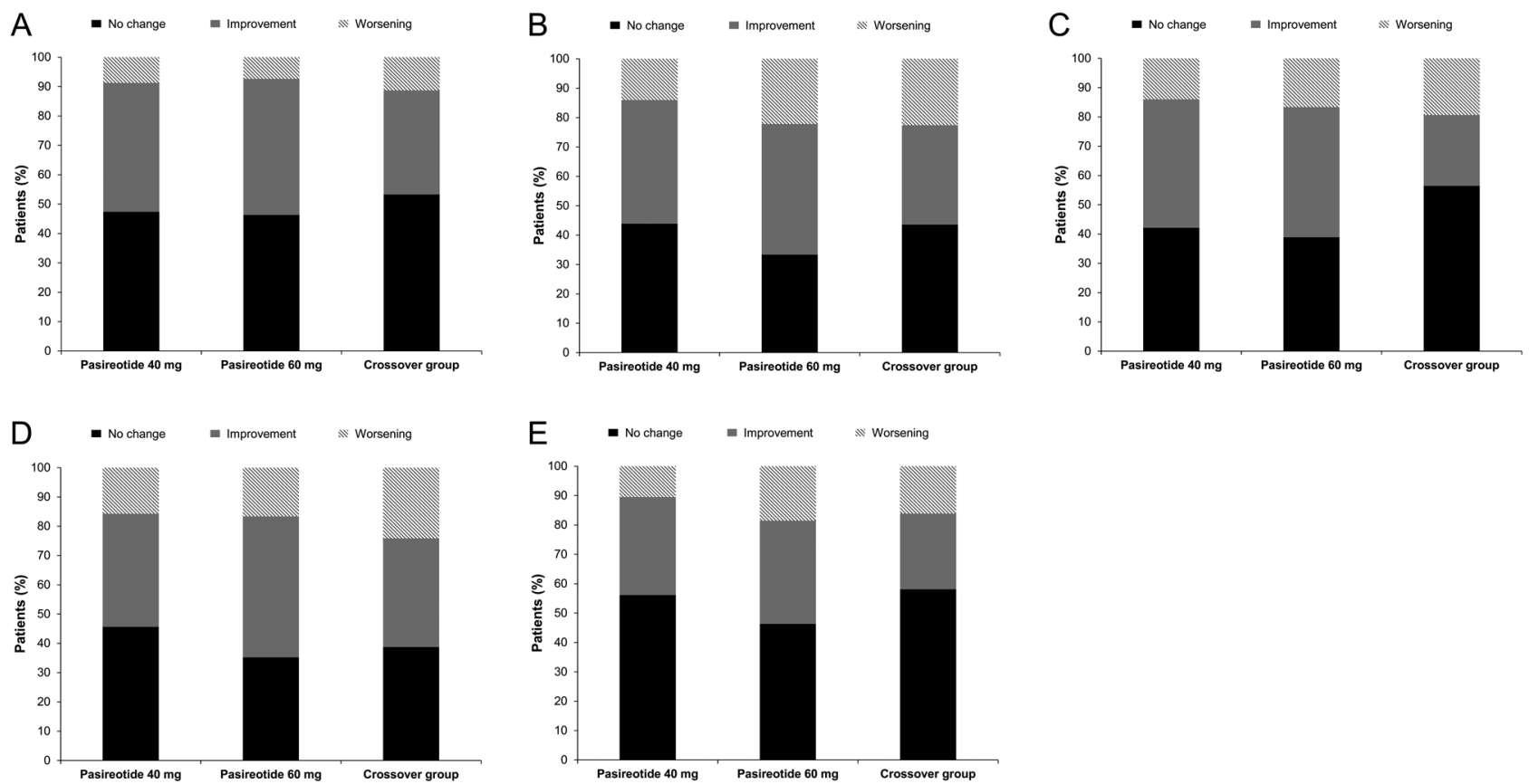

\section{Figure 1}

No change, improvements or worsening in key symptoms of acromegaly: (A) headache; (B) fatigue; (C) perspiration; (D) osteoarthralgia; (E) paraesthesia.

Table 6 Most common adverse events (>10\% in any group) regardless of study drug relationship. Data are presented as $n$ (\%).

\begin{tabular}{|c|c|c|c|c|}
\hline \multirow[b]{2}{*}{ Adverse events } & \multicolumn{2}{|c|}{$\begin{array}{l}\text { Long-acting pasireotide } \mathbf{4 0} \mathbf{~} \mathbf{m g} \text { *, } \\
\qquad n=63\end{array}$} & \multicolumn{2}{|c|}{$\begin{array}{l}\text { Long-acting pasireotide } 60 \text { mg*, } \\
\qquad n=62\end{array}$} \\
\hline & All grades & Grade 3/4 & All grades & Grade 3/4 \\
\hline Total & $61(96.8)$ & $32(50.8)$ & $60(96.8)$ & $33(53.2)$ \\
\hline Hyperglycaemia & 25 (39.7) & $7(11.1)$ & 25 (40.3) & $6(9.7)$ \\
\hline Cholelithiasis & $22(34.9)$ & $3(4.8)$ & $21(33.9)$ & $1(1.6)$ \\
\hline Diabetes mellitus & 20 (31.7) & $1(1.6)$ & $25(40.3)$ & $6(9.7)$ \\
\hline Headache & $18(28.6)$ & 0 & $6(9.7)$ & $3(4.8)$ \\
\hline Diarrhoea & $14(22.2)$ & 0 & $17(27.4)$ & $1(1.6)$ \\
\hline Back pain & $13(20.6)$ & $1(1.6)$ & $7(11.3)$ & $1(1.6)$ \\
\hline Abdominal pain & $10(15.9)$ & $1(1.6)$ & $10(16.1)$ & 0 \\
\hline Anaemia & $10(15.9)$ & $1(1.6)$ & $10(16.1)$ & $2(3.2)$ \\
\hline Hypoglycaemia & $7(11.1)$ & 0 & $7(11.3)$ & $2(3.2)$ \\
\hline Dizziness & $8(12.7)$ & 0 & $3(4.8)$ & 0 \\
\hline Pyrexia & $8(12.7)$ & 0 & $1(1.6)$ & 0 \\
\hline Influenza & $9(14.3)$ & 0 & $9(14.5)$ & 0 \\
\hline Viral upper RTI & $7(11.1)$ & 0 & $9(14.5)$ & 0 \\
\hline Hypertension & $7(11.1)$ & $1(1.6)$ & $4(6.5)$ & $1(1.6)$ \\
\hline Haematuria & $7(11.1)$ & 0 & $2(3.2)$ & 0 \\
\hline Vomiting & $8(12.7)$ & 0 & $1(1.6)$ & 0 \\
\hline Nausea & $7(11.1)$ & 0 & $7(11.3)$ & 0 \\
\hline Arthralgia & $7(11.1)$ & 0 & $9(14.5)$ & $3(4.8)$ \\
\hline Urinary tract infection & $6(9.5)$ & 0 & $5(8.1)$ & 0 \\
\hline Hypercholesterolaemia & $5(7.9)$ & 0 & $6(9.7)$ & 0 \\
\hline Alopecia & $3(4.8)$ & 0 & $8(12.9)$ & 0 \\
\hline
\end{tabular}

\begin{tabular}{|c|c|}
\hline All grades & Grade 3/4 \\
\hline $61(98.4)$ & $31(50.0)$ \\
\hline $16(25.8)$ & $2(3.2)$ \\
\hline 19 (30.6) & $3(4.8)$ \\
\hline $18(29.0)$ & $2(3.2)$ \\
\hline 8 (12.9) & 0 \\
\hline $11(17.7)$ & $1(1.6)$ \\
\hline $3(4.8)$ & $1(1.6)$ \\
\hline $6(9.7)$ & 0 \\
\hline $16(25.8)$ & 0 \\
\hline $4(6.5)$ & 0 \\
\hline $3(4.8)$ & $1(1.6)$ \\
\hline $2(3.2)$ & 0 \\
\hline $5(8.1)$ & 0 \\
\hline $5(8.1)$ & 0 \\
\hline $5(8.1)$ & $2(3.2)$ \\
\hline 0 & 0 \\
\hline 0 & 0 \\
\hline $3(4.8)$ & $1(1.6)$ \\
\hline $3(4.8)$ & 0 \\
\hline $9(14.5)$ & 0 \\
\hline 8 (12.9) & 0 \\
\hline 0 & 0 \\
\hline
\end{tabular}

Hyperglycaemia was defined as a post-baseline FPG measurement of $\geq 126 \mathrm{mg} / \mathrm{dL}$; RTI, respiratory tract infection. *From start of study drug to study end; 'from time of crossover to study end. 
Table 7 Mean FPG and $\mathrm{HbA}_{1 \mathrm{c}}$ values at the end of the extension study and change in actual values in $\mathrm{FPG}$ and $\mathrm{HbA} \mathrm{A}_{1 \mathrm{c}}$ from baseline to end of the extension.

\begin{tabular}{l} 
Baseline diabetic status \\
\hline \\
\hline FPG, mg/dL \\
Diabetic, $n$ \\
Mean (s.D.) \\
Median (range) \\
Pre-diabetic, $n$ \\
Mean (s.D.) \\
Median (range) \\
Normal glucose \\
tolerance, $n$ \\
Mean (s.D.) \\
Median (range) \\
HbA ${ }_{1 c} \%$ \\
Diabetic, $n$ \\
Mean (s.D.) \\
Median (range) \\
Pre-diabetic, $n$ \\
Mean (s.D.) \\
Median (range) \\
Normal glucose \\
tolerance, $n$ \\
Mean \\
Median (range)
\end{tabular}

Long-acting pasireotide $\mathbf{4 0} \mathbf{~ m g}$
Actual

$24 \quad 24$

136 (32)

24

137 (85-189)

9

117 (30)

115 (74-159)

2

125 (1)

125 (124-126)

22 (32)

22 (-43to79)

9

17 (34)

12 (-36to 74$)$

2

$28(4)$

$28(25-30)$

23

$7.0(1.1)$

$6.8(5.6-9.5)$

9

$6.1(0.6)$

$6.1(5.1-7.0)$

2

$5.9(0.1)$

$5.8(5.8-5.9)$

23

$0.8(0.9)$

$1.0(-1.5$ to 2.3$)$

9

$0.5(0.5)$

0.4 (-0.1 to1.3)

2

$0.3(0.1)$

$0.3(0.2-0.3)$

\begin{tabular}{c}
\hline Long-acting pasireotide $60 \mathbf{~ m g}$ \\
Actual
\end{tabular}

21

$168(80)$

21

148 (99-364)

11

133 (38)

$121(96-227)$

2

$158(6) \quad 71(5)$

158 (153-162) 71 (67-74)

$20 \quad 20$

7.9 (1.9)

$7.2(5.8-12.2)$

11

6.7 (2.1)

$6.0(5.6-13.0)$

3

$6.8(1.0)$

$6.5(6.0-7.9)$
$52(84)$

20 (-40to238)

11

28 (38)

20 (-2to131)

20
$1.8(1.9)$
$1.0(-0.3$ to6.1)
11
$1.0(2.1)$
$0.3(-0.2$ to 7.1$)$
3
$1.4(0.9)$
$1.2(0.6-2.4)$

Crossover group

26

152 (50)

$135(97-303)$

10

$116(18)$

$112(92-142)$

1

$96(-)$

$96(-)$

baseline

26

37 (43)

25 (-9to168)

10

15 (16)

8 (-4to44)

1

$10(-)$

$10(-)$

$\begin{array}{ll}29 & 29 \\ 7.3(1.1) & 1.3(1.0) \\ 7.4(5.3-10.1) & 1.3(-0.1 \text { to4.0) } \\ 10 & 10 \\ 6.1(0.5) & 0.4(0.4) \\ 6.2(5.4-6.9) & 0.4(-0.3 \text { to0 } 0.9) \\ 1 & 1 \\ 6.2(-) & 0.6(-) \\ 6.2(-) & 0.6(-) \\ & \end{array}$

During the core and extension phase, the use of concomitant antidiabetic medication was similar across the three treatment arms (pasireotide $40 \mathrm{mg}, n=42$ (66.7\%); pasireotide $60 \mathrm{mg}, n=37$ (59.7\%); crossover (extension only), $n=41(66.1 \%)$ ). In the pasireotide 40 $\mathrm{mg}$, pasireotide $60 \mathrm{mg}$ and crossover groups, respectively, $47.6,46.8$ and $50.0 \%$ received a form of metformin, 23.8, 19.4 and $25.8 \%$ received a dipeptidyl peptidase 4 inhibitor, 27.0, 24.2 and $25.8 \%$ received a sulfonylurea, and 9.5, 8.1 and $8.1 \%$ received insulin and analogues.

Among diabetic patients randomized to either dose of pasireotide or who received pasireotide in the crossover group, use of antidiabetic medication was less frequent after the start of study relative to baseline (Table 9). However, an increase in use of antidiabetic medication after the start of study versus baseline was observed for patients randomized to either dose of pasireotide and who were pre-diabetic or had normoglycaemia at baseline. Pre-diabetic patients in the crossover group also had increased use of antidiabetic medication after the start of the extension phase relative to extension baseline.

\section{Discussion}

Uncontrolled or untreated acromegaly has serious physical (2) and psychological health consequences
(12), placing patients at higher risk of death than the general population $(13,14)$, as well as causing multiple comorbid conditions that lead to impaired quality of life (15). Achieving control of GH and IGF-I is a crucial goal of disease management. Normalizing GH and IGF-I can restore the mortality rate in patients with acromegaly to that of the general population (16) and reduce associated comorbidities (17). Regular monitoring of GH and IGF-I levels and proactive changes to treatment if control is not achieved are important approaches to long-term patient management that support the goal of biochemical control.

Data from the prospective, international PAOLA study provided an opportunity to evaluate the prevalence of comorbidities in a large population of patients with difficult-to-treat acromegaly; eligible patients had uncontrolled acromegaly despite $\geq 6$ months of treatment with a first-generation somatostatin analogue. Diabetes was reported in $67 \%$ of patients enrolled in the study, which is higher than that previously reported for patients with acromegaly (19-56\%) (2). Consistent with previous reports in patients with acromegaly (18), a high proportion of patients enrolled in our study had hypertension (40\%) at baseline, while over one-quarter of patients had one or more lipid-related disorders. Approximately half of patients had three or more comorbid disorders at study entry, indicating a high burden of illness in the patient population. 
Table 8 Number of patients with last available $\mathrm{HbA}_{1 \mathrm{c}}<7 \%$ * at study end, according to baseline diabetic status. Data based on 173 patients who received at least one dose of pasireotide during the extension phase. See Methods section for definitions of diabetic status.

\begin{tabular}{|c|c|}
\hline $\begin{array}{l}\text { Baseline } \\
\text { diabetic status }\end{array}$ & $\begin{array}{l}\text { Long-acting } \\
\text { pasireotide } \\
40 \mathrm{mg}\end{array}$ \\
\hline $\begin{array}{l}\text { Diabetic, } n \\
\qquad \mathrm{HbA}_{1,} n(\%)\end{array}$ & $\begin{array}{c}38 \\
21(55.3)\end{array}$ \\
\hline $\begin{array}{l}\text { Pre-diabetic, } n \\
\qquad \mathrm{HbA}_{1,} n(\%)\end{array}$ & $\begin{array}{c}12 \\
11(91.7)\end{array}$ \\
\hline $\begin{array}{l}\text { NGT, } n \\
\qquad \mathrm{HbA}_{1,}, n(\%)\end{array}$ & $\begin{array}{c}7 \\
6(85.7)\end{array}$ \\
\hline
\end{tabular}

\begin{tabular}{c}
\hline $\begin{array}{c}\text { Long-acting } \\
\text { pasireotide } \\
\mathbf{6 0} \mathbf{~ m g}\end{array}$ \\
\hline 32 \\
$10(31.3)$ \\
12 \\
$9(75.0)$ \\
10 \\
$9(90.0)$ \\
\hline
\end{tabular}

\begin{tabular}{c}
\hline $\begin{array}{c}\text { Crossover } \\
\text { group }\end{array}$ \\
\hline 44 \\
$22(50.0)$ \\
17 \\
$16(94.1)$ \\
1 \\
$1(100.0)$ \\
\hline
\end{tabular}

NGT, normal glucose tolerance.

*Target $\mathrm{HbA}_{1 c}$ level set by the American Diabetes Association and European Association for the Study of Diabetes $(11,12)$.

Although first-generation somatostatin analogues have been effective for many years in the clinic, with biochemical control reported in approximately 55\% of patients (7), a substantial number of patients remain uncontrolled and are therefore exposed to the health risks associated with excess GH and IGF-I. All enrolled patients were uncontrolled, according to assessments of both GH and IGF-I levels, despite prior treatment with a firstgeneration somatostatin analogue. Although the reasons for inadequate control with first-generation somatostatin analogues are multifactorial $(19,20)$, a likely cause is low expression levels of somatostatin receptor subtype (SSTR) 2 on the surface of somatotropinoma cells (21). SSTR5 is also expressed in abundance on somatotropinomas (22), providing rationale for the use of pasireotide in patients uncontrolled on SSTR2-preferential first-generation somatostatin analogues.

In the present study, pasireotide treatment effectively and consistently suppressed GH and IGF-I in a difficult-to- treat patient population for up to 5.8 years of treatment. Notably, of the patients who achieved biochemical control (defined by current recommendations as $\mathrm{GH}<1.0$ $\mu \mathrm{g} / \mathrm{L}$ and normal IGF-I) at least once during the core or extension phase, $65.6 \%$ first responded after more than 6 months of treatment. Over one-quarter (28\%) of patients who received a dose increase of long-acting pasireotide from 40 to $60 \mathrm{mg}$ during the extension were subsequently able to achieve biochemical control. Thus, increasing the dose of pasireotide in patients who have not achieved biochemical control allows more patients to achieve control of GH and IGF-I levels.

Improvements in key acromegaly-associated symptoms were also observed with pasireotide treatment, regardless of baseline symptom severity. This finding is clinically significant given that patients were burdened with a multiplicity of symptoms at study baseline despite prior treatment at the start of the study.

The long-term safety profile of pasireotide was similar to that observed during the 6-month core study; hyperglycaemia, diabetes mellitus, and cholelithiasis were the most common AEs. There were no new safety signals identified in the extension phase compared with the core phase. Importantly, only $13.3 \%$ of patients who received pasireotide during the extension discontinued treatment because of AEs. As pasireotide was used for several years during the study, the low rate of AE-related discontinuations indicates that hyperglycaemia, the most common side effect with pasireotide, is manageable. This finding is of particular clinical significance given that $67.2 \%$ of patients had diabetes mellitus at core baseline, although it should be noted that there are differences in the glycaemic parameters used to define diabetes and pre-diabetes in our study compared with the current guidelines from the American Diabetes Association (23). Furthermore, it is possible that some patients could

Table 9 Number of patients who had antidiabetic medication at baseline or after start of study, according to baseline diabetic status. Data based on 173 patients who received at least one dose of pasireotide during the extension phase. See Methods section for definitions of diabetic status.

\begin{tabular}{|c|c|c|}
\hline \multirow[b]{2}{*}{ Baseline diabetic status } & \multicolumn{2}{|c|}{ Long-acting pasireotide $40 \mathrm{mg}$} \\
\hline & At baseline & $\begin{array}{c}\text { After start of } \\
\text { study }\end{array}$ \\
\hline Diabetic, $n$ & 43 & 43 \\
\hline ADM, $n(\%)$ & $19(44.2)$ & $16(37.2)$ \\
\hline Pre-diabetic, $n$ & 12 & 12 \\
\hline ADM, $n(\%)$ & $0(0.0)$ & $4(33.3)$ \\
\hline $\mathrm{NGT}, n$ & 8 & 8 \\
\hline ADM, $n(\%)$ & $0(0.0)$ & $4(50.0)$ \\
\hline
\end{tabular}

\begin{tabular}{|c|c|}
\hline \multicolumn{2}{|c|}{ Long-acting pasireotide $60 \mathrm{mg}$} \\
\hline At baseline & $\begin{array}{c}\text { After start of } \\
\text { study }\end{array}$ \\
\hline 37 & 37 \\
\hline 17 (45.9) & $14(37.8)$ \\
\hline 13 & 13 \\
\hline $0(0.0)$ & $4(30.8)$ \\
\hline 12 & 12 \\
\hline $0(0.0)$ & $3(25.0)$ \\
\hline
\end{tabular}

\begin{tabular}{cc}
\hline \multicolumn{2}{c}{ Crossover group } \\
\hline $\begin{array}{c}\text { At extension } \\
\text { baseline }\end{array}$ & $\begin{array}{c}\text { After start of } \\
\text { extension }\end{array}$ \\
\cline { 1 - 2 } 24 & 44 \\
$22(50.0)$ & $15(34.1)$ \\
17 & 17 \\
$2(11.8)$ & $6(35.3)$ \\
1 & 1 \\
$0(0.0)$ & $0(0.0)$ \\
\hline
\end{tabular}

ADM, antidiabetic medication; NGT, normal glucose tolerance. 
have been incorrectly classified as diabetic in our study based on their use of antidiabetic medications, such as metformin, which is frequently prescribed for patients with insulin resistance without a diagnosis of diabetes. The prolonged exposure to pasireotide during the course of the study may also account for the rate of drug-related serious AEs observed, while the low discontinuation rate in the study in spite of this likely reflects the significant burden of uncontrolled acromegaly; patients eligible for this extension study had uncontrolled acromegaly while receiving maximal-dose octreotide or lanreotide for at least 12 months.

As previously mentioned, diabetes mellitus is one of the most common comorbidities to occur in patients with acromegaly and exposes patients to increased risk of mortality. Management of diabetes and other comorbidities is an important therapeutic goal in the treatment of acromegaly (3); while treatment with firstgeneration somatostatin analogues typically increases FPG levels during the first month of therapy, attainment of disease control (defined in this instance as mean fasting GH $\leq 2.5 \mu \mathrm{g} / \mathrm{L}$ and normal age- and sex-matched IGF-I) after 12 months of treatment is strongly associated with maintenance of glucose levels or even a reduction in some patients (24). Conversely, glucose levels tend to increase in most pasireotide-treated patients. Pasireotideassociated hyperglycaemia typically occurs within the first month of treatment (25) and is manageable with antidiabetic medication in most instances or reversible upon discontinuation of pasireotide if uncontrolled with antidiabetic treatment. In our study, most patients had an $\mathrm{HbA}_{1 \mathrm{c}}$ level below the target set by the American Diabetes Association $(<7 \%)$ at their last assessment, demonstrating that they were not exposed to prolonged periods of hyperglycaemia. Vigilant monitoring of glucose levels during pasireotide treatment is required, with prompt action taken as necessary, starting with the initiation of antidiabetic medication.

Pegvisomant, a GH-receptor antagonist, is an alternative therapeutic option for patients with impaired glucose tolerance (26). Although pegvisomant has been shown to control IGF-I levels in at least $63.2 \%$ of patients after 5 years of treatment and improve glucose tolerance, its mechanism of action results in significantly increased GH levels (27). Additionally, pegvisomant therapy requires monitoring of hepatic function and evaluation of tumour size, although tumour progression is rare. Combination therapy also presents a viable therapeutic alternative, which is increasingly employed in patients with uncontrolled acromegaly. Treatment with various combinations of cabergoline, octreotide/lanreotide and pegvisomant, and more recently pasireotide and pegvisomant, have been shown to be efficacious in subsets of patients with acromegaly $(28,29,30)$.

Given the chronic nature of acromegaly, prolonged administration of medical therapy is often necessary to maintain long-term suppression of GH and IGF-I levels. In the current study, pasireotide demonstrated long-term sustained suppression of both GH and IGF-I levels, with improvements in key symptoms and a low AE-related discontinuation rate suggestive of acceptable tolerability. At present, pasireotide is indicated in the EU for adult patients with acromegaly for whom surgery has failed or is not an option and who are inadequately controlled on other first-generation somatostatin analogues. In the United States, pasireotide can be given as a first-line medical therapy in patients for whom surgery has failed or is not an option.

With several effective options available for the treatment of acromegaly, identifying the right treatment for the right patient is critical. In addition to key prospective and real-world studies providing efficacy and safety data, cost-effectiveness analyses are also valuable in facilitating clinical decision making. One study reviewed current cost-effectiveness analyses of acromegaly treatments, highlighting several key limitations with these studies (31). As such, there remains a need for additional, robust cost-effectiveness analyses to be conducted for all medical treatment options for acromegaly.

In the core phase of this study, patients were randomized to receive double-blind pasireotide 40 or 60 $\mathrm{mg}$, or continued treatment with open-label octreotide/ lanreotide. The unavoidable difference in blinding between pasireotide and octreotide/lanreotide recipients is a limitation of this study.

In conclusion, long-acting pasireotide demonstrated a positive benefit/risk profile for up to 5.8 years of treatment in patients with acromegaly uncontrolled on prior first-generation somatostatin analogue therapy who had a high prevalence of baseline comorbidity, including glucose-related disorders.

\section{Supplementary materials}

This is linked to the online version of the paper at https://doi.org/10.1530/ EJE-19-0762.

\section{Declaration of interest}

A C has received consultancy and speaker fees from Novartis, Pfizer and Ipsen. M D B has served on steering committees for Chiasma, Ipsen and Novartis and has received speaker fees from Ipsen and Novartis, as well as 
clinical research grants from Ipsen, Novartis and Pfizer. T B has received institutional research support from Pfizer and consultancy/lectureship fees from Novartis, Ipsen, Strongbridge and Pfizer. M F is the principal investigator for research grants to Oregon Health \& Science University received from Chiasma, Crinetics, Ionis, Novartis and Pfizer and an ad hoc scientific consultant to Chiasma, Crinetics, Ionis, Ipsen, Novartis and Pfizer. M G has served as a principal investigator in clinical trials conducted by Novartis. G R has received institutional research support from Novartis and Ipsen and consultancy and lectureship fees from Novartis, Ipsen, Chiasma and Pfizer. I S has received research grants and consultancy and lectureship fees from Novartis, Chiasma and Pfizer. M R G has received research grants and speaker fees from Novartis, Ipsen and Pfizer, has attended advisory boards for Novartis and lonis, and has been a principal investigator in clinical trials conducted by Novartis and Ipsen. J F, P G and A M P are employees of Novartis.

\section{Funding}

This study was funded by Novartis Pharma AG. Financial support for medical editorial assistance was provided by Novartis Pharmaceuticals Corporation.

\section{Data sharing}

Novartis is committed to sharing with qualified external researchers access to patient-level data and supporting clinical documents from eligible studies. These requests are reviewed and approved by an independent review panel on the basis of scientific merit. All data provided are anonymized to respect the privacy of patients who have participated in the trial, in line with applicable laws and regulations. This trial data availability is in accordance with the criteria and process described on www.clinicalstudydatarequest.com.

\section{Acknowledgements}

The authors thank Thomas Walker, Mudskipper Business Ltd for medical editorial assistance with this manuscript.

\section{References}

1 Sanno N, Teramoto A, Osamura RY, Horvath E, Kovacs K, Lloyd RV \& Scheithauer BW. Pathology of pituitary tumors. Neurosurgery Clinics of North America 200314 25-39, vi. (https://doi.org/10.1016/s10423680(02)00035-9)

2 Colao A, Ferone D, Marzullo P \& Lombardi G. Systemic complications of acromegaly: epidemiology, pathogenesis, and management. Endocrine Reviews 200425 102-152. (https://doi. org/10.1210/er.2002-0022)

3 Katznelson L, Laws Jr ER, Melmed S, Molitch ME, Murad MH, Utz A, Wass JA \& Endocrine Society. Acromegaly: an Endocrine Society clinical practice guideline. Journal of Clinical Endocrinology and Metabolism 201499 3933-3951. (https://doi.org/10.1210/jc.20142700)

4 Colao A, Vandeva S, Pivonello R, Grasso LF, Nachev E, Auriemma RS, Kalinov K \& Zacharieva S. Could different treatment approaches in acromegaly influence life expectancy? A comparative study between Bulgaria and Campania (Italy). European Journal of Endocrinology 2014 171 263-273. (https://doi.org/10.1530/EJE-13-1022)

5 Gadelha MR, Kasuki L, Lim DST \& Fleseriu M. Systemic complications of acromegaly and the impact of the current treatment landscape: an update. Endocrine Reviews 201940 268-332. (https:// doi.org/10.1210/er.2018-00115)

6 Oberg K \& Lamberts SW. Somatostatin analogues in acromegaly and gastroenteropancreatic neuroendocrine tumours: past, present and future. Endocrine-Related Cancer 201623 R551-R566. (https://doi. org/10.1530/ERC-16-0151)

7 Carmichael JD, Bonert VS, Nuño M, Ly D \& Melmed S. Acromegaly clinical trial methodology impact on reported biochemical efficacy rates of somatostatin receptor ligand treatments - a meta-analysis. Journal of Clinical Endocrinology and Metabolism 201499 1825-1833. (https://doi.org/10.1210/jc.2013-3757)

8 Colao A, Auriemma RS, Pivonello R, Kasuki L \& Gadelha MR. Interpreting biochemical control response rates with first-generation somatostatin analogues in acromegaly. Pituitary 201619 235-247. (https://doi.org/10.1007/s11102-015-0684-z)

9 Colao A, Bronstein MD, Freda P, Gu F, Shen CC, Gadelha M, Fleseriu M, van der Lely AJ, Farrall AJ, Hermosillo Reséndiz K et al. Pasireotide versus octreotide in acromegaly: a head-to-head superiority study. Journal of Clinical Endocrinology and Metabolism 201499 791-799. (https://doi.org/10.1210/jc.2013-2480)

10 Gadelha MR, Bronstein MD, Brue T, Coculescu M, Fleseriu M, Guitelman M, Pronin V, Raverot G, Shimon I, Lievre KK et al. Pasireotide versus continued treatment with octreotide or lanreotide in patients with inadequately controlled acromegaly (PAOLA): a randomised, phase 3 trial. Lancet: Diabetes and Endocrinology 20142 875-884. (https://doi.org/10.1016/S22138587(14)70169-X)

11 Giustina A, Barkan A, Casanueva FF, Cavagnini F, Frohman L, Ho K, Veldhuis J, Wass J, von Werder K \& Melmed S. Criteria for cure of acromegaly: a consensus statement. Journal of Clinical Endocrinology and Metabolism 200085 526-529. (https://doi.org/10.1210/ jcem.85.2.6363)

12 Leon-Carrion J, Martin-Rodriguez JF, Madrazo-Atutxa A, Soto-Moreno A, Venegas-Moreno E, Torres-Vela E, Benito-López P, Galvez MA, Tinahones FJ \& Leal-Cerro A. Evidence of cognitive and neurophysiological impairment in patients with untreated naive acromegaly. Journal of Clinical Endocrinology and Metabolism 201095 4367-4379. (https://doi.org/10.1210/ jc.2010-0394)

13 Holdaway IM, Bolland MJ \& Gamble GD. A meta-analysis of the effect of lowering serum levels of GH and IGF-I on mortality in acromegaly. European Journal of Endocrinology 2008159 89-95. (https://doi.org/10.1530/EJE-08-0267)

14 Sherlock M, Ayuk J, Tomlinson JW, Toogood AA, Ragon-Alonso A, Sheppard MC, Bates AS \& Stewart PM. Mortality in patients with pituitary disease. Endocrine Reviews 201031 301-342. (https://doi. org/10.1210/er.2009-0033)

15 T'Sjoen G, Bex M, Maiter D, Velkeniers B \& Abs R. Health-related quality of life in acromegalic subjects: data from AcroBel, the Belgian registry on acromegaly. European Journal of Endocrinology 2007157 411-417. (https://doi.org/10.1530/EJE-07-0356)

16 Holdaway IM, Rajasoorya RC \& Gamble GD. Factors influencing mortality in acromegaly. Journal of Clinical Endocrinology and Metabolism 200489 667-674. (https://doi.org/10.1210/jc.2003031199)

17 Varadhan L, Reulen RC, Brown M \& Clayton RN. The role of cumulative growth hormone exposure in determining mortality and morbidity in acromegaly: a single centre study. Pituitary 201619 251-261. (https://doi.org/10.1007/ s11102-015-0700-3)

18 Bondanelli M, Ambrosio MR \& degli Uberti EC. Pathogenesis and prevalence of hypertension in acromegaly. Pituitary 2001 4 239-249. (https://doi.org/10.1023/a:1020798430884)

19 Colao A, Auriemma RS, Lombardi G \& Pivonello R. Resistance to somatostatin analogs in acromegaly. Endocrine Reviews 201132 247-271. (https://doi.org/10.1210/er.2010-0002)

20 Gadelha MR, Kasuki L \& Korbonits M. Novel pathway for somatostatin analogs in patients with acromegaly. Trends in Endocrinology and Metabolism 201324 238-246. (https://doi. org/10.1016/j.tem.2012.11.007) 
21 Wildemberg LE, Neto LV, Costa DF, Nasciuti LE, Takiya CM, Alves LM, Rebora A, Minuto F, Ferone D \& Gadelha MR. Low somatostatin receptor subtype 2 , but not dopamine receptor subtype 2 expression predicts the lack of biochemical response of somatotropinomas to treatment with somatostatin analogs. Journal of Endocrinological Investigation 201336 38-43. (https://doi. org/10.3275/8305)

22 Chinezu L, Vasiljevic A, Jouanneau E, Francois P, Borda A, Trouillas J \& Raverot G. Expression of somatostatin receptors, SSTR2A and SSTR5, in 108 endocrine pituitary tumors using immunohistochemical detection with new specific monoclonal antibodies. Human Pathology 201445 71-77. (https://doi. org/10.1016/j.humpath.2013.08.007)

23 American Diabetes Association. 2. Classification and diagnosis of diabetes: standards of medical care in Diabetes-2019. Diabetes Care 201942 S13-S28. (https://doi.org/10.2337/dc19-S002)

24 Colao A, Auriemma RS, Savastano S, Galdiero M, Grasso LF, Lombardi G \& Pivonello R. Glucose tolerance and somatostatin analogues treatment in acromegaly: a 12-month study. Journal of Clinical Endocrinology and Metabolism 200994 2907-2914. (https:// doi.org/10.1210/jc.2008-2627)

25 Silverstein JM. Hyperglycemia induced by pasireotide in patients with Cushing's disease or acromegaly. Pituitary 201619 536-543. (https://doi.org/10.1007/s11102-016-0734-1)

26 Melmed S, Bronstein MD, Chanson P, Klibanski A, Casanueva FF, Wass JAH, Strasburger CJ, Luger A, Clemmons DR \& Giustina A. A
Consensus Statement on acromegaly therapeutic outcomes. Nature Reviews: Endocrinology 201814 552-561. (https://doi.org/10.1038/ s41574-018-0058-5)

27 van der Lely AJ, Hutson RK, Trainer PJ, Besser GM, Barkan AL, Katznelson L, Klibanski A, Herman-Bonert V, Melmed S, Vance ML et al. Long-term treatment of acromegaly with pegvisomant, a growth hormone receptor antagonist. Lancet 2001358 1754-1759. (https://doi.org/10.1016/s0140-6736(01)06844-1)

28 Lim DS \& Fleseriu M. The role of combination medical therapy in the treatment of acromegaly. Pituitary 201720 136-148. (https://doi. org/10.1007/s11102-016-0737-y)

29 Muhammad A, van der Lely AJ, Delhanty PJD, Dallenga AHG, Haitsma IK, Janssen JAMJL \& Neggers SJCMM. Efficacy and safety of switching to pasireotide in acromegaly patients controlled with pegvisomant and first-generation somatostatin analogues (PAPE study). Journal of Clinical Endocrinology and Metabolism 2018103 586-595. (https://doi.org/10.1210/jc.2017-02017)

30 Muhammad A, Coopmans EC, Delhanty PJD, Dallenga AHG, Haitsma IK, Janssen JAMJL, van der Lely AJ \& Neggers SJCMM. Efficacy and safety of switching to pasireotide in acromegaly patients controlled with pegvisomant and somatostatin analogues: PAPE extension study. European Journal of Endocrinology 2018179 269-277. (https://doi.org/10.1530/EJE-18-0353)

31 Leonart LP, Borba HHL, Ferreira VL, Riveros BS \& Pontarolo R. Costeffectiveness of acromegaly treatments: a systematic review. Pituitary 201821 642-652. (https://doi.org/10.1007/s11102-018-0908-0)

Received 26 September 2019

Revised version received 6 March 2020

Accepted 27 March 2020 